Artículo de investigación

Cuestiones de filosofía

ISSN: 0123-5095

Vol. 2 - No. 19

Julio - dciembre, año 2016

pp. $15-30$

\title{
Fundamentos para la posibilidad de una verdad artística: una lectura, en clave filosófica, de los orígenes de la producción audiovisual*
}

\author{
Fundament for the possibility of an artistic truth: \\ A philosophical reading into the origins of audiovisual \\ production
}

Muriel Vásquez**

Universidad de Buenos Aires

Argentina

Fecha de recepción: 9 de mayo del 2016

Fecha de evaluación: 3 de junio del 2016

Fecha de aceptación: 15 de septiembre del 2016

* Grupo UBACyT "Programa para el mejoramiento de la enseñanza de la filosofía: La enseñanza universitaria de la filosofía”. Código de identificación del proyecto: 20020100100518. Pertenencia institucional: Universidad de Buenos Aires. Facultad de Filosofía y Letras. Instituto de Filosofía Dr. Alejandro Korn. Buenos Aires. Argentina.

** Profesora de enseñanza media y superior en Filosofía. Universidad de Buenos Aires. Facultad de Filosofía y Letras. Buenos Aires. Argentina. murielvazquez@ hotmail.com 


\title{
Resumen
}

El artículo aborda algunas líneas de reflexión que vinculan la producción audiovisual con la filosofía, partiendo del concepto de "juguete filosófico" propuesto por Oubiña (2009) para aplicar a la invención de una serie de aparatos que se consideran antecesores del cine. Se realiza una crítica a la designación de la contradicción de términos presente en el par dicotómico juego y filosofía-idea que presenta Oubiña en su propuesta, pero que sistematiza Schjaer (2012) en una reflexión posteriora partir de un análisis conceptual que propone nuevos sentidos para esos términos, fundamentando esta crítica en las reflexiones de dos filósofos escasamente citados en el área del cine: Lyotard (1989) y Wittgenstein (1958).

La hipótesis central de la autora es, por lo tanto, que no es real ni aparente la contradicción entre los términos "juguete" y "filosófico", como tampoco lo es entre los conceptos “juego" y “filosofía” o entre los verbos “jugar” y “filosofar”. Además, la autora justifica y fundamenta que tanto en la prehistoria, como en la historia y en lo que llama la poshistoria del cine (haciendo referencia a una arqueología de los medios que permite llegar hasta las formas actuales de producción audiovisual) no solo puede rastrearse un elemento originario científico y técnico, sino que también hay allí un componente de tipo filosófico (que no necesariamente debe traducirse como "ilusorio" o "lúdico", como sostiene Oubiña/Schjaer) que es aquel que posibilita la caracterización estética del cine. Este componente filosófico trasciende las manifestaciones materiales de la obra y se asienta en una verdad de tipo ontológico que explica y sostiene la expresión artística cinematográfica.

Palabras clave: Audiovisual y filosofía, Juguete filosófico, verdad artística

\begin{abstract}
This article reflects upon the link between audiovisual production and philosophy, drawing from the concept of "philosophical toy", as proposed by Oubiña (2009), a concept which can be related to the creation of a series of devices that are considered to be close predecessors of cinema. A critique to the commonly considered contradictory relationship between the dichotomous word pair game and philosophy is made. This idea, first proposed by Oubiña, was later structured by Schjaer (2012) in one of his works. Drawing from a conceptual analysis, this article proposes new meanings to those terms. This paper is supported on the critical and reflective perspective of Lyotard (1989) and Wittgenstein (1958), two
\end{abstract}


philosophers who are rarely cited in the field of cinema. The author's main hypothesis is that there is neither a real nor apparent contradiction between the terms "toy" and "philosophical", as there is not between the concepts of "game" and "philosophy "or between the verbs "to play" and "to philosophize". The author also justifies that both during the prehistory and history of cinema, as well as in what she calls posthistory (term referred to the archeology of media that leads to the current forms of audiovisual production), not only can a technical and scientific element be found at its origins, but also a philosophical element can be tracked, one that shouldn't be simply understood as "illusory" or "ludic", as stated by Oubiña/Schjaer, as it allows for an aesthetic characterization of cinema. This philosophical component transcends the material manifestations of the cinematic work and is based on an ontological truth, which explains and sustains the artistic, cinematographic expression.

Key words: Audiovisual media and philosophy, philosophical toy, artistic truth

\section{Cine y Juegos: Del lenguaje al DeSeo}

Se aprende el juego observando cómo juegan otros. Pero decimos que se juega según tales y cuales reglas porque un espectador puede extraer estas reglas de

la práctica del juego (...) ¿Pues de qué modo está cerrado el concepto de juego? ¿Qué es aún un juego y qué no lo es ya? ¿Puedes indicar el límite? No.

Puedes trazar uno: pues no hay aún ninguno trazado (...) Así jugamos precisamente el juego. (Me refiero al juego de lenguaje con la palabra “juego")

(Wittgenstein, 1958 pp. 20-24)

"Por otra parte, el cine es un lenguaje" (Bazin, 1994, p. 30)

Oubiña propone un análisis histórico y reflexivo de los trabajos y estudios sobre el movimiento que realizaron Muybridge y Marey, y sostiene que durante el siglo XIX, los denominados philosophical toys son los encargados de promover o acompañar el desarrollo de ellos, fluctuando entre una curiosidad lúdica y una argumentación científica. Para este autor existe una "aparente contradicción que subyace a esos términos obligados a coexistir bajo la unidad de una definición" (2009, p. 39). Schjaer hace una lectura de esta afirmación de Oubiña en la que creo que es menester detenerse, puesto que contribuye a la argumentación que intentaré sostener. En la afirmación de Oubiña, la contradicción, además de 
aparente, es subyacente; es decir, se encuentra por debajo del par dicotómico, como si fuera la condición de posibilidad de existencia de este. Schjaer (2012, p. 66) hace una lectura sutilmente diferente, sosteniendo que el nombre "juguetes filosóficos" implica una doble naturaleza, siendo términos aparentemente contradictorios; en este caso lo contradictorio son los términos, no a nivel subterráneo, sino lingüístico (semántico, podríamos decir). La diferencia entre las afirmaciones de estos autores, aunque tenue, abre, en términos filosóficos, dos caminos de reflexión: el que nos conduce a la metafísica y el que nos conduce a la filosofía del lenguaje. Dos disciplinas, dos áreas de estudio, de la misma actividad crítico-reflexiva: la filosofía ${ }^{2}$.

Vamos a comenzar analizando la cuestión de la contradicción de términos. Pareciera ser que en la afirmación de Schjaer subyace una premisa que asigna definiciones diferentes, y a la vez contrapuestas, a términos que no necesariamente lo son. Parecería que jugar y filosofar son incompatibles, que jugar es poner a disposición de la imaginación una serie de elementos que pueden o no vincularse, y filosofar implica pensar rigurosa y sistemáticamente. En principio resulta dificultoso encontrar una definición adecuada para el término "juego" o "juguete" (que en definitiva es aquello con lo cual se lleva a cabo un juego, la materialidad con la que jugar es posible), puesto que no hay una reglamentación estipulada de antemano para la aplicación de estos términos. Sostiene Wittgenstein que "no está regulada la aplicación de la palabra; no está regulado el 'juego' que jugamos con ella. No está en absoluto delimitado por reglas; (...) ¿Cómo le explicaríamos a alguien qué es un juego?" (1958, p. 23). Por esto mismo, si nos concentramos en la definición de la palabra "juego" encontramos que dentro de ella podríamos incluir tanto lo que hace un bebé que aún no razona y solo mueve sus miembros frente a un objeto móvil, como aquello que realiza un ajedrecista frente a una serie de piezas con determinados movimientos posibles, y no otros, pensando una estrategia específica con la finalidad de ganarle a un adversario; entre estos posibles extremos, una variedad, si no infinita al menos ilimitada, de actividades que formarían parte de la misma "familia" de términos. Wittgenstein plantea esta dificultad en la definición de esta manera:

2 Dejo fuera del análisis las cuestiones relacionadas con la formalidad lógica para la cual contradicción, estrictamente hablando, implicaría la afirmación de la verdad de algo y de su negación al mismo tiempo y en el mismo sentido (en este caso, "juego y no juego" o "filosofía y no filosofía"). Está claro que la complejidad que se analiza en este trabajo está vinculada con la necesidad de esclarecer cuál es el sentido en que se utiliza el término "juego" y en cuál se piensa la filosofía. 
Considera, por ejemplo, los procesos que llamamos "juegos". Me refiero a juegos de tablero, juegos de cartas, juegos de pelota, juegos de lucha, etc. ¿Qué hay común a todos ellos? No digas: 'Tiene que haber algo común a ellos o no los llamaríamos juegos', sino mira si hay algo común a todos ellos. Pues si las miras no verás, por cierto, algo que sea común a todos, sino que verás semejanzas, parentescos $\mathrm{y}$, por cierto, toda una serie de ellos (...). ¿Son todos ellos entretenidos? (...) ¿O hay siempre un ganar y perder, o una competición entre los jugadores? (...) qué papel juegan la habilidad y la suerte? (...). Podemos ver cómo los parecidos surgen y desaparecen (1958, pp. 22-23).

Oubiña habla de lo inquietante que es pensar que grandes conceptos -como los filosóficos- puedan surgir de un pasatiempo infantil -el juego-. Podríamos cuestionar la necesaria asociación que el autor hace del término "juego" o "juguete" exclusivamente con algo infantil. Su libro está dedicado a dos personas que, según el autor, conocen "el secreto de todos los juegos", y cabría preguntarse, antes que por el origen o el sentido del término, más bien por el secreto, que de hecho hacia el final de su trabajo Oubiña lo asocia con el fotograma. El término secreto alude a algo misterioso, casi mágico, a algo relacionado con la curiosidad, porque un secreto despierta la curiosidad. Cabría preguntarse por qué restringir la curiosidad a algo infantil; propongo extender esta capacidad al género humano de cualquier edad. Asumo, por tanto, que el juego, cualquiera fuera e independientemente de cómo se lo defina, apela a un componente de curiosidad y, como tal, está vinculado a un deseo o a un placer. El secreto de todos los juegos tiene más bien que ver con esto último, incluso si el juego que se juega es filosófico; por lo tanto, con base en la reflexión que presenta Wittgenstein, propongo tener en cuenta una concepción amplia del concepto juego en la que lo esencial se vincula con la curiosidad, el placer y el deseo.

Además de la dificultad que presenta la definición de "juego", resulta problemático hallar, o acordar, una definición para el término filosofía (o "filosófico", en tanto se predique de algo material, en este caso). Si hacer filosofía -denominaremos a esta actividad filosofar-consistiera solo en pensar rigurosa y sistemáticamente (al igual que lo requeriría un partido de ajedrez), quedarían por fuera de esta definición no solo determinadas formas de hacer filosofía, sino también el pensamiento de ciertos filósofos aceptados como tales por la historia de las ideas (como serían, por ejemplo, los diálogos platónicos, el pensamiento nietzscheano o los aforismos de Wittgenstein). 
Propongo aquí atribuir un sentido amplio al término filosofía, para afirmar que la contradicción con “juego" no es ni aparente ni real. Entiendo que la actividad de filosofar implica el ejercicio o la acción del pensamiento sobre diversos aspectos de la realidad -cosas o estados de cosas-. Ahora bien, si la filosofía se ocupa de cuestiones inherentes a la realidad humana y muchas veces tan cotidianas y recurrentes que suelen ser ignoradas o naturalizadas, entonces la reflexión y problematización de ellas, para constituirse en objeto de interés de la curiosidad inherentemente humana, deberá estar acompañada por generadores de placer, es decir, estimulantes del deseo. El impulso dinámico, el deseo, está relacionado con lo que Lyotard, filósofo francés contemporáneo, denomina una "estructura de presencia y ausencia" (1989, p. 88). El deseo es conciencia de una ausencia. La potencialidad que implica la existencia del deseo hace referencia a la representación de algo que no está. En el caso del filosofar, esta ausencia es la de la sabiduría (la sofía - $\sigma \circ \phi 1 \alpha-$, que se busca o desea -filos, $\phi \imath \lambda \circ \zeta-)$, la conciencia de que no hay un "objeto" de indagación, sino que, en el ejercicio del filosofar únicamente hay una búsqueda. Esta exploración debería estar orientada a "buscar por qué buscar". En este sentido, el deseo se constituye en la condición de posibilidad del filosofar, no para "desear la sabiduría, sino para desear el deseo" (1989, p. 95). Esta es, justamente, la propuesta del filósofo: recordarnos que la actividad filosófica consiste en una búsqueda constante del deseo de desear, por el mero gusto de hacerlo. Lyotard señala que el deseo es una relación que simultáneamente une y separa sus términos, haciéndolos estar "el uno en el otro y a la vez el uno fuera del otro" (1989, p. 89). Con lo cual, esta relación no implica una unidad cerrada y total, sino una mediación, un proceso ${ }^{3}$. El deseo que atraviesa esta concepción de la filosofía es un movimiento, una tensión dinámica que "mantiene unido lo separado o separado lo unido" y, según Lyotard, este es el "movimiento que atraviesa la filosofía, y sólo abriéndose a él y para abrirse a él se filosofa" (1989, p. 97). Desde esta perspectiva, la actividad filosófica no está dedicada a intentar encontrar un objeto de análisis y explicarlo pretendiendo abarcar su totalidad. En el movimiento que implica una búsqueda filosófica -aplicada a cualquier aspecto de la realidad-, el deseo se desea a sí mismo, interrogándose a la vez que desarrolla su propio movimiento.

Cuando en filosofía hacemos referencia al deseo no podemos dejar de retomar el diálogo platónico Banquete, en el que Platón nos advierte que Eros, el amor, nos permite ser conscientes con respecto a una falta, y esta conciencia nos proporciona la capacidad de desear lo que se cree que se necesita (Platón 2008: 200 A-C). En función de la doble naturaleza originaria de Eros, el mismo es presentado como un impulso dinámico de deseo de las cosas buenas y bellas, de la sabiduría. 
En la actividad del filosofar, solo se puede saber que se continúa buscando respuesta a preguntas que se vuelven a hacer una y otra vez, y que se vuelven a hacer porque es la búsqueda de la respuesta la que se desea en realidad, y no la respuesta ni la pregunta. A este movimiento subyace una idea lúdica, una actitud de juego del filósofo que respalda su interés con base en una curiosidad cuyo sostenimiento le genera placer. Al ejercicio de filosofar, entendido de esta manera, le es inmanente el deseo, porque la actividad filosófica planteada en estos términos implica un dejarse llevar por el deseo de búsqueda, y consistiría en "obedecer plenamente al movimiento del deseo", recogiendo cada vez y en cada inclinación de mediaciones que supone el movimiento todo aquello que se revela, que se hace visible, se materializa. El filósofo recoge, en esta tensión del movimiento del deseo, el resultado de la actividad que lleva a cabo en su interior -su pensamiento, su imaginación y también sus emociones- y expresa, manifiesta, exterioriza, podríamos decir, materializa, el camino recorrido, de manera más o menos sistemática, más o menos formal, en lo que la historia de las ideas ha dado en llamar pensamientos filosóficos ${ }^{4}$.

En conclusión, me permito afirmar que no es contradictorio el par dicotómico juguete-filosófico, en términos semánticos o aparentes; no lo es porque existen definiciones posibles -amplias-de los términos "juego" y "filosofía" que permiten asociar ambas actividades, pero, además, muestro aquí que existe una forma de entender el sentido del filosofar-en términos reales o existenciales podríamos decir-que lo asocia a una actividad lúdica, en la medida que se asienta sobre la base del movimiento del deseo. Se juega para satisfacer deseos, se filosofa para mantener el deseo en movimiento de búsqueda. ¿Con qué finalidad se hace cine?, ¿con qué objetivo se lo ve?, ¿cuál es el sentido de la producción audiovisual?, ¿satisface deseos?, ¿tiende a mantenerlos en movimiento de búsqueda?

4 Retomando el pensamiento de Wittgenstein sobre la cuestión de convenir una definición para la filosofía, nos dice el autor que "(...) la filosofía es una lucha contra el embrujo de nuestro entendimiento por medio de nuestro lenguaje (...) El hecho fundamental es aquí: que establecemos reglas, una técnica, para un juego, y que entonces, cuando seguimos las reglas, no marchan las cosas como habíamos supuesto. Que por tanto nos enredamos, por así decirlo, en nuestras propias reglas. Este enredarse en nuestras reglas es lo que queremos entender, es decir, ver sinópticamente (...) La filosofía expone meramente todo y no explica ni deduce nada. Puesto que todo yace abiertamente, no hay nada que explicar. Pues lo que acaso esté Oculto, no nos interesa (...) El trabajo del filósofo es compilar recuerdos para una finalidad determinada" (1958, pp. 30-32). 


\section{CINE Y VERDAD: DEL APARATO AL ESPECTADOR}

En el final del siglo veinte, el arte que usa imágenes se instala en un extraño tiempo intermedio (...)

Para nosotros, el contenido de verdad objetiva de (...) una secuencia fílmica ya no vale más como una luz. Técnicas sofisticadas para manipular y simular imágenes han traído desavenencias profundas entre lo que se ve y la persona que lo ve (Siegfried Zielinski, Máquinas buenas y malas)

“AAcaso el deseo podría satisfacerse con una imagen?

La respuesta es que, tal vez, el cine no muestra

acciones verdaderas o falsas, sino ficcionales. Y es precisa esa ficción para que tenga lugar el acontecimiento estético" (Oubiña, 2009, p. 124).

En los juguetes filosóficos pueden encontrarse dos dimensiones heterogéneas vinculadas al desarrollo de las investigaciones sobre el movimiento; por un lado, hay necesariamente en estas indagaciones un componente científico-técnico asociado con los dispositivos maquínicos que van haciendo posible, en primer lugar, la captura del instante y, luego, la ilusión del movimiento cuando este instante se convierte en fotograma de una cinta de película y se combina con otros ${ }^{5}$. Los philosophical toys, en tanto aparatos, son los encargados de producir lo que se denomina imágenes técnicas ${ }^{6}$. Schjaer define estos aparatos como "máquinas que capturan y representan el mundo en imágenes” (2012, p. 66). En este sentido los dispositivos maquínicos a los que hago alusión son aparatos que parecerían tener cierta capacidad no solo técnica, sino también una especie de poder de tipo mágico.

5 Este componente maquínico del arte cinematográfico hace manifiesto el engaño, la apariencia de no ser, deja en evidencia la ficcionalización. "En un sentido, su única finalidad es producir la ilusión del movimiento a partir de imágenes estáticas; pero, al mismo tiempo, esa ilusión esta a la vista y permite ser analizada. De modo tal que, en el mismo instante en que se produce el engaño, el propio dispositivo lo deja en evidencia." (Oubiña, 2009, p. 46)

6 No me detendré aquí en este asunto pero creo muy interesante el desarrollo que hace Flusser sobre la posición ontológica de los aparatos para entender su definición no solamente a partir de su significado etimológico. El escritor sostiene que en su aspecto ontológico, es decir, en su nivel de realidad y existencia, los aparatos son objetos producidos, es decir, objetos conducidos hacia el mundo de lo cultural desde el natural, mediante la intervención del trabajo y producción humanos (Flusser, 1975, p. 24) 
Es necesario asumir que hay, ciertamente, algo contradictorio en la producción cinematográfica; sin embargo, creo que no se trata de la contradicción entre lo científico y lo lúdico o entre lo lúdico y lo filosófico, porque ya vimos que una definición posible de juego, que implique una amplitud de aplicación del término, así como una definición profunda de filosofía, que la asocie con el deseo, y en este sentido se acerque al juego en el campo del placer que ambos provocan en el desarrollo de su movimiento intrínseco, permite que más bien exista un acercamiento entre estos ámbitos en la producción cinematográfica e, incluso, que en esa relación radique su sentido más propio, y hasta podríamos decir, incluso, su fundamento estético, no obstante lo cual, existe algo contradictorio en la producción audiovisual que tiene que ver con la vida y la muerte, con un aspecto metafísico que vincula lo que es en este instante y lo que ya-no-es. Lo perturbador, sostiene Schjaer, es que el cine "remite al mundo de las sombras, de los espectros, y, al mismo tiempo, reproduce la vida" (2012, p. 72). En la producción audiovisual lo que se ve está constantemente sugiriendo lo que no se ve, es decir, aquello que está fuera de campo. En este juego entre lo que es y lo que no es, se evidencia la dificultad para pensar la cuestión de la verdad de la imagen cinematográfica. Aun así, intentaré desarrollar lo más claramente posible la perspectiva al respecto que sostengo en este trabajo.

Sostiene Schjaer, siguiendo a Oubiña, que "el orden del cine no es el de la verdad ni del saber, sino del secreto" (2012, p. 72). Vemos aquíque se recurre nuevamente al concepto de secreto. En términos metafísicos podemos entender lo secreto como lo subyacente, lo que está por debajo de todos los accidentes que hacen que algo sea contingentemente lo que es, y que implica, además, su esencia -o ousía, en términos aristotélicos-. Aquello que lo hace ser lo que es y sin lo cual eso sería otra cosa diferente ${ }^{7}$. Los aparatos productores de imágenes técnicas revelan que "lo que se ve siempre implica una distancia, una disparidad, un diferimiento. Siempre hay una latencia (...) lo que se ve oculta una realidad más compleja" (Oubiña, 2009, p. 44). En este sentido, los aparatos que han sido incluidos en el concepto de "juguete filosófico" envuelven la expresión material de

7 En este sentido, los accidentes -las manifestaciones externas o exteriores- pueden modificarse, y así alterar la apariencia de la cosa o el estado de cosas, pero su secreto continúa haciendo que algo sea ontológicamente lo que es. Hablamos ya de la estructura subyacente al deseo que implica un vínculo presencia-ausencia. Este vínculo podría ser entendido como el secreto del deseo, puesto que es lo que subyace al movimiento de búsqueda que este implica. 
una idea. Esta idea es la siguiente: hay una presencia que denota una ausencia, por lo tanto, hay deseo. Sin embargo, la dificultad está en la relación que esta idea tiene con el concepto de verdad. Podemos preguntarnos: ¿por debajo del movimiento del deseo, de lo uno que busca lo otro, hay algo verdadero?, ¿cuál es el tipo de verdad que se manifiesta en la producción cinematográfica?

Hay una apariencia fundacional en la producción audiovisual que depende exclusivamente de su capacidad para materializar una realidad inexistente (en el sentido de ya-no-existente), para re-producirla ${ }^{8}$. Como vemos, la cuestión es compleja, porque si bien las películas no son imágenes en movimiento, sino "imágenes del movimiento que se suceden unas a otras, produciendo la ilusión de una continuidad allí donde solo hay instantes fijos y discontinuos" (Oubiña, 2009, p. 130), su verdad es perturbadora, porque se nos hace presente, en tanto se revela ante nuestra mirada, pero es una verdad aparente, ficticia, ficcional. Dice Oubiña que "el cine es mentira porque reproduce la superficie de las cosas" (2009, p. 130), reproduce lo superficial y no el secreto, lo aparente y no lo real, los accidentes y no la ousía.

Afirmé en el apartado anterior que el deseo implica la conciencia de una ausencia. Si pensamos en la producción audiovisual no puede escapársenos el hecho de que es una manifestación artística que siempre está haciendo referencia a otra cosa que no está allí, es decir, también hay conciencia de una ausencia, por el hecho de que es re-producción de lo que no está. Todas las formas de producción audiovisual, incluyendo las formas actuales vinculadas al arte contemporáneo, se fundamentan en una estructura de presencia y ausencia. Y sobre esta base se erige su vínculo con el deseo y el juego que este lenguaje artístico propone al espectador ${ }^{9}$. Al acercarnos al terreno del placer y el deseo, el cine nos despierta inicialmente asombro y luego mantiene nuestra atención y creencia. Hay en el lenguaje cinematográfico una narración, una escritura con imágenes, y hay una necesidad de que el espectador acepte entrar en una confusa seducción (una "alucinación

8 El cine, o las producciones audiovisuales en general, a nivel ontológico, continúan siendo una secuencia de imágenes fijas que se ponen en movimiento, y que, además, "al ponerse en movimiento intentan repetir un instante pasado $\mathrm{y}$, al hacerlo, evidencian que eso sucedió (puesto que fue registrado) aunque, a la vez, ya no tiene lugar (puesto que solopuede ser reproducido)" (Oubiña, 2009, p.130).

9 Según Schjaer "(...) el cine funciona como una "forma de seducción en el orden del relato: es necesario cautivar al espectador a través de procedimientos narrativos, que solo pueden ser articulados a partir de un ordenamiento de tipo formal" (2012, p. 77). 
consciente", dice Schjaer). Es necesario que la actitud del espectador sea la de la consciencia del autoengaño, y hablamos de autoengaño porque la decisión de ver una película implica conocer el funcionamiento y la ontología del cine: es una ilusión de realidad, pero que necesita de la actitud fiel de creencia del espectador para obtener los objetivos propuestos (sean estos entretener, emocionar, reflexionar o reponer críticamente) $)^{10}$.

Schjaer asocia la producción cinematográfica con la invitación a un juego dirigida hacia el espectador, un juego que, en lugar de satisfacer deseos -motivación que oportunamente puede incluso verse frustrada al ver un film-se encarga de hacerlos entrar en tensión, de invitarlos a ingresar en un movimiento de "lo uno que busca lo otro", de lo que se ve que busca lo que no se ve, una tensión dinámica que "mantiene unido lo separado o separado lo unido", como sostenía Lyotard ${ }^{11}$. Y en este caso, lo unido en la imagen es la vida y la muerte, lo que está y lo que ya no está, la presencia de una ausencia. La presencia de un mundo de sombras que pone a trabajar la imaginación, el pensamiento y las emociones del espectador. En palabras de Schjaer:

(...) el cine no satisface deseos; más bien juega con ellos, seduce al deseo y lo deja en suspenso. Arroja al espectador a un abismo, a un mundo de sombras, que provoca la imaginación del espectador. El cine no puede (o no debe) domesticar al espectador, quitarle esa necesidad de imaginar constantemente (2012, p. 73).

Para Schjaer, el problema del cine es un problema de creencia: depende siempre de la manera como el espectador se posiciona frente a las imágenes ${ }^{12}$ en este sentido, elespectador no sería un personaje secundario o alguien sin importancia

10 Lo que no debemos olvidar como espectadores es que el cine es arte, y como tal, se realiza probablemente con más voluntad compositiva y narrativa que aspiración a mostrar una verdad objetiva de tipo científica, o incluso un pensamiento sistemático y analítico de tipo filosófico. Pero esto no significa que el cine no revele una verdad, ni sea un tipo de pensamiento, todo lo contrario, y esto es lo que intento expresar en este trabajo.

11 Sobre la tensión de lo que se ve y lo que no se ve, piensa Oubiña que "más que una afirmación, una sospecha. Esa tensión permanece en la imagen, agazapada, como si se tratara de su "inconsciente óptico"” (2009, p. 93).

12 "Saberse siempre consciente del modo incompleto en que las imágenes capturan y hacen visible el mundo y completar, en el mismo movimiento, esa ausencia con algo del propio espectador. Es ontológicamente necesaria esa insuficiencia para que el espectador pueda habitar las imágenes" (Schjaer, 2012, p. 73). 
en el mecanismo cinematográfico. Si bien la realización de un film está en manos de un equipo que implica una mediación no solo material —en la medida que incluye objetos técnicos, máquinas de producción de imágenes, aparatos o "juguetes”-, sino también humana y múltiple, hay además una parte de esa realización sujeta al público a quien está dirigido. Porque se juega con Otro, se expresa o se habla, por medio del lenguaje cinematográfico, $a$ Otro $^{13}$. Cuando se re-produce una película existe la necesidad de completar la representación de la realidad que se muestra ante los ojos del espectador con la propia imagen mental de todo lo que no está-dicho, mostrado, representado- en la película. Podríamos decir, entonces, que existen tres vectores al momento de analizar la cuestión de la verdad en la reproducción de una película; en primer lugar, la mirada de quien la hizo, representada en las imágenes proyectadas; en segundo lugar, la "interpretación" que hace la máquina, su punto de vista, su mediación, y, finalmente, la acción del espectador: su forma de mirar, su actitud y la interpretación de esa película que finalmente se hace emoción -pasión y deseo- en él.

En definitiva, a efectos de analizar lo verdadero en la producción cinematográfica, poco importa la decisión o el objetivo del director de la película y el deseo de transmitir un mensaje por medio de ella (si eso existiese). Lo que termina de darle sentido a la existencia de la representación cinematográfica es la actitud del espectador de aceptar esa porción de realidad que se despliega ante sus ojos como una verdad; la actitud de creer que estoy siendo engañado, de aceptar las reglas de ese juego y ver luego qué se hace con eso (si lo disfruto, si me aburro, si lo cuestiono, entre otras opciones). Para Schjaer, el espectador, en esta actitud de creencia, se deja arrastrar por la narración de la película, por ese misterio que consiste en una forma de reproducción de la realidad. El cine necesita que el espectador crea que se está re-produciendo una realidad (aunque la película no tenga intenciones realistas). Se reproduce la realidad del que cuenta o narra, del que actúa, del que escribe, pero, sobre todo, se produce la realidad que construye el que ve, que viendo, interpreta ${ }^{14}$.

En la acción del espectador (a esta afirmación subyace la idea de un espectador que no recibe pasivamente lo que se le presenta ante los ojos, sino que el cine

13 "El espectador permite que el cine funcione como espectáculo, es decir, que el cine funcione" (Schjaer, 2012, p. 72).

14 Una re-producción que es tal porque tiene una producción previa: la del montaje de las escenas que componen la narración completa. 
interpela a, y requiere de, un espectador activo y comprometido) se revela el mismo movimiento que Lyotard encuentra en la filosofía: el de la búsqueda del deseo de desear, por el mero gusto de hacerlo. La relación con lo deseado que propone el juego filosófico -incluso cuando media en él la producción audiovisuales un movimiento hacia lo ausente. Quiero decir que, tanto si este movimiento lo desarrolla quien hace cine, como quien concurre a verlo, puede tratarse de un juego y puede ser filosófico. Todo esto convierte la experiencia en una expresión artística particular a la que subyace una verdad en tensión de tipo hermenéutica, es decir, envuelta en el círculo de interpretación triádico propuesto por cada vector que antes mencioné (producción/dispositivo maquínico/espectador). En la medida que los programas de los aparatos que posibilitan la producción audiovisual están compuestos por símbolos (Flusser, 1975, p. 28), hacerlos funcionar implica necesariamente jugar con esos símbolos, combinarlos de diferentes maneras, tanto que permitan crear nuevas posibilidades ${ }^{15}$. Hay un juego que se lleva a cabo al utilizar los aparatos que producen imágenes; este juego, que va más allá de la utilización de una herramienta, implica una combinación simbólica que adquiere valor estético en la medida que es expresión de su verdad intrínseca: tiene el secreto de hacer ver lo que es -presencia-, lo que ya no es -ausencia- y lo que no es en este momento -tensión y movimiento del deseo imaginado-.

\section{Conclusiones}

\section{Cine y filosofía: jugar a pensar}

Nombrar no es aún en absoluto una jugada en el juego de lenguaje -como tampoco colocar una pieza de ajedrez es una jugada en el ajedrez-. Puede decirse: Al nombrar una cosa todavía no se ha hecho nada. Tampoco tiene ella un nombre, excepto en el juego (Wittgenstein , 1958, p. 19)

"El ajedrecista juega con las piezas del ajedrez; el fotógrafo, con la cámara. Esta no es una herramienta, sino un juguete; y el fotógrafo no es un trabajador, sino

15 “El fotógrafo (...) puede dedicarse al juego de la cámara (...) de la cámara se 'supera' el aspecto de herramienta, y el hombre solo trata el aparato en cuanto juguete (...) Hay entonces dos programas entrelazados dentro de la cámara: uno mueve la cámara para producir automáticamente las imágenes, y el otro le permite al fotógrafo jugar (...) La cámara está hecha de material (...) no es esta dureza física lo que la convierte en un juguete (...) son las reglas, el programa, los que lo hacen un juego (...)" (Flusser, 1975, pp. 29-30). 
un jugador: no es un homo faber, sino homo ludens. Solo que el fotógrafo no juega con su juguete, sino contra éste (Flusser, 1975, p. 28).

Partiendo de las afirmaciones de Oubiña y Schjaer y del análisis de las diferencias particulares en ellas, establecí en este trabajo dos líneas de reflexión; en primer lugar, una de tipo semántico, en donde me detengo en la crítica a la contradicción de términos (entre juego y filosofía) que estos autores proponen; este análisis resulta importante porque la forma de entender el concepto "juguete filosófico" constituye una premisa central a la hora de fundamentar la razón de ser de la producción cinematográfica. El concepto que presenta Oubiña -que le da título a la obra que cito aquí-engloba un conjunto de aparatos que dan origen científico al desarrollo del cine; por lo tanto, la elección y utilización de esos términos no puede pasar inadvertida por un análisis crítico que intente ir más allá de la exploración científico-técnica. La utilización del concepto juguete filosófico implica una carga teórica que es menester desentrañar. Si estos aparatos son el origen del cine en sentido técnico, también lo son en sentido metafísico. Por esto mismo, mi análisis me llevó a otra instancia de reflexión, en segundo lugar, en la que afirmo que el cine, si bien da cuenta de un componente científico-técnico, ese es el encargado de revelar o expresar un elemento filosófico, no solo en su origen, sino también en su desarrollo.

La afirmación de la existencia de este componente filosófico es lo que me permite analizar el fenómeno cinematográfico desde todas las problemáticas incluidas en la reflexión filosófica tradicional -metafísica, gnoseología, ética, estética, etc.-. Lo filosófico del cine se asienta en una verdad ontológica (estética) que aparece, o se revela como tal, porque está mediada por el aparato. Es una verdad que sobrepasa las distintas formas de entender el concepto (verdad por correspondencia, por coherencia, interpretativa), porque la producción audiovisual en general es un fenómeno artístico complejo que pone en juego diversas formas de realización. Estas prácticas diversas en la producción audiovisual están mediadas por aparatos, y, como plantea Flusser, un aparato es un juguete complejo cuyo juego consiste en combinar símbolos dentro del programa que utilice. El autor sostiene que "los aparatos son cajas negras que simulan el pensamiento humano en cuanto juego que combina símbolos (...) cajas negras científicas que juegan a pensar" (1975, pp. 30-31). Estas afirmaciones me llevan a plantear, finalmente, la problemática que emerge de las líneas críticas que propongo en el trabajo: ¿Cómo el cine y la filosofía pueden jugar a pensar?

En el segundo capítulo del libro de Oubiña, que en este trabajo analizo, aparece planteada la dicotomía “acción o pensamiento", que está presentada en el desarrollo 
del texto como contradictoria. De hecho, dice Oubiña, "la acción parecería ser enemiga del pensamiento, y el pensamiento, un obstáculo insalvable para la acción” (2009, p. 53). En principio podríamos preguntarnos si pensar no estaría dentro del campo semántico de lo que se denomina una acción. La actividad de tipo contemplativo no deja de ser un ejercicio (ya lo había presentado así Aristóteles). Pero además cabe preguntarnos en qué categoría entrarían tanto el pensar filosófico como el pensar propio delarte cinematográfico. En este trabajo propuse una noción amplia de filosofía que la entiende como ejercicio o verbo, como filosofar; por lo tanto, y como tal, es una acción. Además de la filosofía, el arte, en general, también tiene una función crítica, porque implica una forma de representación que no intenta reflejar o reproducir la realidad, sino, más bien, mostrar o revelar una imagen de esta que la interpele para desnaturalizarla y problematizarla ${ }^{16}$; sin embrago, creo que la contradicción entre lo abstracto (del pensamiento) y lo singular (lo intransferible de los actos) no solo no es tal, sino que incluso funciona casi como una condición de posibilidad para que el cine piense desde su propia materialidad; tanto como la actividad filosófica, que solo es posible desde unas determinadas coordenadas espacio-temporales del filósofo y desde la historia de las ideas que la precede (ya desde Hegel podemos rastrear la idea de un pensar situado).

Además, debemos aceptar que también es necesario, para que exista un pensamiento filosófico, el ejercicio de la imaginación, que permita a una mente crítica y dispuesta vincular ideas e interpretar conceptualmente con mayor libertad y amplitud las problemáticas que le incumben. Oubiña sostiene que el nombre philosophical toys es "expresión de una actividad en la que todavía se mantenían unidas la dimensión del juego y la del pensamiento", en la medida en que hay, no solo una puesta en ejercicio de la capacidad imaginativa del creador, sino también un componente científico y, por lo tanto, una mediación propia de la formalidad conceptual. Sin embargo, para Oubiña "el cine se convertirá rápidamente en lo opuesto de la filosofía: uno será pura acción concreta allí donde la otra reclama lo abstracto y la reflexión" (2009, p. 39). "Pura acción concreta", dice Oubiña. Poiesis -poiesiz- le llamaban los griegos. Actividad que sigue determinadas reglas y que tiene la finalidad de obtener un producto que está pensado y estipulado de antemano. Lo opuesto para Oubiña son la abstracción y la reflexión; sin embargo, no podemos dejar de notar que también abstraer y reflexionar son acciones, acciones propias del pensamiento, de la imaginación, de la razón, del conocimiento. Acciones que pueden hacerse concretas

16 Para el caso de las películas, Oubiña dirá: "no existen para celebrar nuestra visión del mundo, sino para interrogarla y ponerla en cuestión” (2009, p. 111). 
en resultados expresables en palabras y pensables para otros. No es lo mismo. No voy a sostener aquí que cine y filosofía sean idénticos, pero rechazo el término opuestos, con base en que negamos la contradicción entre jugar y filosofar. El cine piensa, y puede pensar, filosóficamente. La filosofía implica un tipo de juego y una forma de reflexión que puede ser asimilada al pensamiento cinematográfico. La filosofía puede reflexionar sobre el cine o incluso cinematográficamente ${ }^{17}$.

\section{REFERENCIAS}

Bazin, A. (1994). ¿Qué es el cine? Capítulo 1: Ontología de la imagen fotográfica Madrid: Rialp

Flusser, V. (1975). Hacia una filosofía de la fotografía. México: Trillas

Lyotard, J. F. (1989). ¿Por qué filosofar?, Conferencia 1: “PPor qué desear?”. Barcelona: Paidós.

Oubiña, D. (2009). Una juguetería filosófica. Cine, cronofotografía y arte digital. Buenos Aires: Manantial

Platón (2008). Banquete, traducción de Martínez Hernandez, M. Madrid: Gredos.

Schjaer, S. (2012). "Fotografía y cine: Máquina y espectáculo", en LAFERLAJ. y Reynal, S. (comp.): Territorios Audiovisuales. Cine, video, televisión, documental, instalación, nuevas tecnologías, paisajes mediáticos. Buenos Aires: Libraria

Wittgenstein, L. (1958). Investigaciones filosóficas. Barcelona: Altaya

Zielinski, S. (2006). Genealogías, visión, escucha y comunicación. Bogotá: Uniandes

17 La definición de una forma de pensamiento cinematográfica para la filosofía podría abrir nuevos caminos de reflexión en este trabajo que nos llevarían a otros lugares pensables. Bastará aquí recordar los trabajos de Cabrera J. (1999) Cine: 100 años de filosofía. Una introducción a la filosofía a través del análisis de películas. Barcelona: Gedisa, Cabrera J. (2009) "Para una des-comprensión filosófica del cine: el caso Inland de David Lynch". Enl@ce, Revista Venezolana de Información, Tecnología y Conocimiento, Año 6, N. 2, Mayo-Agosto 2009, pág. 117 y Matamoros Franco N.M. (2002) "Cine y filosofía: el acto ideatorio como evento fílmico", Revista Signos filosóficos, N 7, U.A.M., Iztapalapa, DF, México, pág. 175-188; como ilustración de este tipo de reflexión. 